the same as at the close of 1903 . The Committee again urges the membership in general to participate in the work of increasing the numerical strength by inducing new persons to join. The result of the presentation of one new name by each member is easy to calculate.

The membership at the close of 1903 was . . . . . . . . I,605

New members secured in Ig04 . . . . . . . . . . IOI

$\sqrt{\mathbf{1 , 7 0 6}}$

Loss by death, resignation and non-payment of dues . . . . . 109

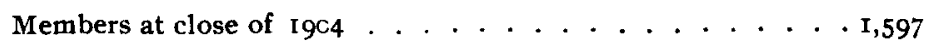

ALHXANDER KRUMBHAAR,

Chairman.

PHIL,A DEL,PHIA, January 2, 1905 .

\title{
REPORT OF THE COMMITTEE ON SECTIONAL ARRANGEMENTS FOR THE YEAR I9O4.
}

\section{To the Board of Managers:}

Your Committee on Sectional Arrangements respectfully reports that during the year 1904 the Sections of the Institute held thirty-four meetings, nearly all of which were devoted to the consideration and discussion of subjects of strictly technical or scientific interest. The pages of the Journal afford the best evidence of the value of the work thus accomplished.

The Committee is pleased to be able to report that the interest of the members in this branch of the Institute's activity is well maintained. The report of the secretaries is appended hereto.

JAMES Christie,

Chairman Com. on Sectional Arrangements.

PhIMADEL,PHIA, January 2, 1905.

\section{APPENDIX.}

To the Committee on Sectional Arrangements:

The several Sections have had thirty-four meetings during 1904, all being joint sessions of the entire Section body. In respect of attendance and the general character of the subjects discussed, the past year will compare favorably with any of its predecessors. The Journal has been enriched by numerous contributions of value from this source.

Some modification of present methods will be introduced in 1905 , for the purpose of keeping more prominently before the members the idea of the separate organization of the individual Sections, which, naturally, has been forced more or less into the background by the placing of all the special routine work hitherto done by each Section in the hands of an Executive Committee appointed by the Committee on Sectional Arrangements. With the restoration of these functions, it is believed that the only serious criticism that has been brought against the "joint session" plan as now in vogue, will be met satisfactorily.

PhILADELPHIA, January 3, 1905.

WM. H. WAHL, for the Secretaries. 